\title{
Multiple Endocrine Neoplasia Type 2A
}

National Cancer Institute

\section{Source}

National Cancer Institute. Multiple Endocrine Neoplasia Type 2A. NCI Thesaurus. Code C3226.

Multiple endocrine neoplasia caused by mutation of the RET gene. Patients develop medullary thyroid carcinomas, and may also develop pheochromocytomas and parathyroid gland hyperplasia. 